\title{
ESCOLA PÚBLICA E CLASSES SOCIAIS NO BRASIL ATUAL
}

\author{
PUBLIC SCHOOL AND SOCIAL CLASSES IN BRAZIL TODAY \\ LÉCOLE PUBLIQUE ET LES CLASSES SOCIALES AU BRÉSIL D’AUJOURD'HUI \\ ESCUELA PÚBLICA Y CLASES SOCIALES EN EL BRASIL ACTUAL
}

Décio Azevedo Marques de Saes*

\section{RESUMO}

Este texto visa a tratar o fracasso escolar, no Brasil atual, como um fenômeno social, o que implica buscar as suas causas sociais. A nossa conclusão é que, ampliando-se consideravelmente a oferta de educação pública no nível fundamental e, ao mesmo tempo, mantendo-se o padrão de classe média do ensino, só pode predominar a tendência à manutenção e mesmo ao aumento do fracasso escolar das crianças de origem popular, incapazes de se elevar até o padrão de ensino definido pelo aparelho de Estado capitalista. E é dificil imaginar a reformulação desse padrão, já que a classe média, altamente influente no campo educacional, necessita do fracasso escolar das outras classes sociais para intensificar a sua própria valorização econômica e social.

Palavras-chave: Escola pública. Classe média. Proletariado. Fracasso escolar.

* Doutor em Sociologia pela École des Hautes Études en Sciences Sociales (1974). Pós-Doutor na Université de Paris I - Panthéon - Sorbonne (1980). Livre-docente na Universidade Estadual de Campinas (1983). Professor titular da Faculdade de Educação e Letras da Universidade Metodista de São Paulo (mdsaes@uol.com.br). 
Meu objetivo, neste texto, é empreender uma análise sociológica da relação entre a Escola Pública e as classes sociais, na sociedade capitalista brasileira da atualidade. Não tenho a intenção de apontar, aqui, soluçōes para os supostos "problemas" vividos pela Escola Pública no Brasil atual. A discussão sobre "o que fazer" na Escola Pública ou com a Escola Pública é altamente relevante de um ponto de vista político. Ela exige, porém, dos debatedores, que aprofundem a análise política da relação entre "o que fazer" com a Escola Pública e "o que fazer" com o modelo vigente de sociedade.

Neste texto, vou me limitar a analisar o modo de presença de certas classes sociais na Escola Pública no Brasil atual. A premissa teórica subjacente a esse esboço é a de que, por mais que a engenharia social construa soluçōes regeneradoras para a Escola Pública, existem limites sociais, ideológicos e políticos que o funcionamento da Escola Pública não pode franquear em qualquer sociedade capitalista, inclusive o Brasil.

\section{O PARADOXO VIVIDO PELO SISTEMA NACIONAL DE EDUCAÇÃO: A COEXISTÊNCIA INSOLÚVEL ENTRE "SUCESSO" E "FRACASSO"}

Ao analisarmos o desempenho atual do sistema nacional de educação e do sistema de educação pública, constatamos que diferentes atores políticos avaliam de modo extremamente contrastado esse desempenho. De um lado, os governos de todos os escalóes (federal, estadual, municipal) festejam aquilo que lhes parece ser o resultado concreto das políticas governamentais de ampliação contínua da oferta de serviços educacionais: a quase universalização do acesso ao ensino fundamental. $\mathrm{O}$ dado quantitativo oficial - a inscrição de $96,5 \%$ das crianças de sete a 14 anos no ensino fundamental - é utilizado no discurso governamental para sugerir a virtual concretização do direito universal à educação no Brasil. De outro lado, educadores e intelectuais se empenham em demonstrar, com apoio em material empírico abundante, que a outra face do sucesso do sistema educacional no plano da democratização do acesso à educação fundamental é o fracasso do sistema educacional no plano do desempenho escolar dos alunos.

Mais especificamente: muitos educadores e intelectuais constatam que, nos últimos 20 anos, ocorreu uma considerável ampliação das vagas do ensino público, não só no nível fundamental como também no nível médio. Porém, esses pesquisadores apontam, ao mesmo tempo, que a democratização do acesso ao ensino fundamental não resultou numa alteração qualitativa da configuração da pirâmide educacional brasileira. Alunos ditos "pobres" - isto é, oriundos das classes trabalhadoras manuais - estão relegados a uma trajetória escolar curta, que inclui a conclusão do ensino fundamental ou, no máximo, do ensino técnico de nível médio. Já os alunos ditos "ricos" (classe média-média ou classe média-alta, classes proprietárias) conseguem cumprir uma trajetória escolar longa, que abrange o ensino médio e o ensino superior (e, nos dias que correm, não só a graduação como também, cada vez mais, a pós-graduação). 
Há dados oficiais abundantes sobre as elevadas taxas de retardo, evasão e fracasso, registradas no sistema escolar brasileiro. Esclareça-se, desde logo, que o sistema de ciclos implantado no nível do ensino fundamental não pode contrabalançar essa taxa, já que tal sistema: a) ainda tem caráter minoritário em escala nacional (é adotado apenas em cinco estados e abrange apenas $21 \%$ dos alunos do ensino fundamental); b) mantém a possibilidade de reprovação em dois pontos de inflexão do sistema de educação básica: a quarta e a oitava séries do ensino fundamental.

Vejamos agora a distribuição relativa de entidades públicas e entidades privadas dentro do sistema nacional de educação. No nível do ensino superior, o setor privado não só prepondera amplamente sobre o setor público, como também procura sufocá-lo. Já nos níveis do ensino fundamental e do ensino médio, o sistema de educação pública é altamente preponderante, a ponto de, em 2003 (segundo dados de uma pesquisa da Unesco), ${ }^{1}$ a Escola Pública oferecer, no Brasil, $87 \%$ das matrículas do ensino médio.

Portanto, sendo o sistema de educação pública amplamente predominante no nível fundamental e no médio, pode-se concluir que o padrão de funcionamento da Escola Pública é responsável pela reprodução, no Brasil, de uma pirâmide educacional que reserva uma trajetória escolar curta à maioria social e uma trajetória escolar longa à minoria social.

Passemos, agora, a uma nova questão: de que modo o funcionamento concreto da Escola Pública, já relativamente democratizada quanto ao acesso, ${ }^{2}$ produz um resultado final tão antidemocrático? Dados de pesquisas recentes sugerem que se reproduz regularmente, dentro da Escola Pública brasileira, uma diferença de desempenho entre alunos "ricos" e alunos "pobres" (isto é, entre classe média e proletariado). ${ }^{3}$ Por isso, os alunos da Escola Pública que passam pelo funil do vestibular numa universidade pública, ainda que enfrentando numa concorrência desigual os alunos das grandes escolas particulares, tendem a pertencer predominantemente à classe média.

Sobre essa diferença, há dados bastante significativos. Segundo o PNAD de 2001, $85 \%$ dos alunos com renda mensal média inferior a meio salário mínimo ainda não chegaram, aos 14 anos, à oitava série. E o boletim "Quantidade sem qualidade", divulgado pelo Preal (Programa de Promoção da Reforma Educativa na América Latina e Caribe) no seminário "Ações de Responsabilidade Social em Educação: Melhores Práticas na América Latina”, informa que a discrepância de nota entre alunos ricos e alunos pobres é de $18 \%$, favoravelmente aos alunos ricos. A importância sociológica dos dados sobre a diferença entre as classes sociais poderia ser relativizada, caso os alunos oriundos das classes trabalhadoras manuais fossem uma minoria dentro da Escola Pública. Dados de pesquisas recentes, entretanto, comprovam exatamente o contrário. Conforme levantamento realizado pelo projeto Gestão para o Sucesso Escolar, em 2004 os alunos das classes de renda C, D e E representavam $80 \%$ dos inscritos na quarta série, e $74 \%$ dos inscritos na 8 a série, em escolas públicas de São Paulo e Santa Catarina. ${ }^{4}$ 
Ora, se os alunos de origem proletária são a maioria esmagadora nas Escolas Públicas, até serem excluídos no processo de passagem ao ensino médio, devemos concluir que o propalado "fracasso" da Escola Pública consiste, antes de tudo, no fracasso em levar a massa dos estudantes proletários a uma trajetória escolar longa. Diante desse fracasso de amplo significado social, o fracasso da Escola Pública em colocar os seus alunos, perante o vestibular, em igualdade de condições com os alunos das grandes escolas particulares, é um fracasso secundário, que concerne principalmente (embora não exclusivamente) a alguns setores declinantes da classe média.

O proletariado estudantil só chega minoritariamente ao vestibular nas universidades públicas, pois já foi excluído do sistema escolar bem antes disso, por força da lógica de funcionamento desse sistema, bem como das suas próprias condiçôes materiais de existência.

É importante que se mantenha sempre em mente a distinção entre essas duas formas de "fracasso" do ensino público, já que grande parte das críticas à "baixa qualidade do ensino público" resulta do diagnóstico do fracasso da Escola Pública em preparar o aluno sobrevivente (isto é, da classe média) para o vestibular público; e, não, do diagnóstico de fracasso da Escola Pública em incorporar o proletariado ao processo educacional.

\section{AS CAUSAS SOCIAIS PROFUNDAS DO FRACASSO DA ESCOLA PÚBLICA EM INCORPORAR O PROLETARIADO AO PROCESSO EDUCACIONAL}

Agora, podemos passar à questão central deste texto. É possível que a Escola Pública, numa sociedade capitalista qualquer, promova de fato a incorporação do proletariado ao processo educacional, permitindo-lhe concretizar uma trajetória escolar completa? Essa questão só pode ser respondida depois de termos analisado, no plano estritamente teórico, o lugar invariante da Escola Pública na sociedade capitalista em geral.

As revoluções políticas burguesas dos séculos XVII, XVIII e XIX não levaram à criação imediata de um sistema de educação pública que estivesse fundado nos princípios do ensino público, gratuito e obrigatório; e que propiciasse educação igual e de boa qualidade para todos. Os sistemas nacionais de educação, emergentes na fase de formação da sociedade burguesa moderna, tinham um caráter claramente dual. Em países como a França, a Inglaterra e a Alemanha, a "escola dos ricos" coexistia com a "escola dos pobres", ainda na segunda metade do século XIX.

Em fins do século XIX, o ideal da Escola Única - isto é, de uma Escola que fornecesse educação igual e de boa qualidade para todas as classes sociais - se difunde no aparelho estatal de alguns países onde o Estado concorre com a Igreja Católica pelo controle do processo educacional. A burocracia de Estado, defensora da "formação patriótica" (tendo em vista objetivos inclusive militares), postula uma educação igualitária, voltada para a formação de cidadãos, e critica a "formação cristã", pouco 
comprometida com tais ideais. Na França, o ciclo de instauração da Escola Única se iniciou com o governo republicano moderado de Jules Ferry, que em 1882-1883 instaurou o ensino primário público, gratuito e obrigatório. Tal ciclo continuou durante os governos radicais subseqüentes, que aperfeiçoaram a Lei Jules Ferry com uma série de medidas complementares; e chegou a um importante estágio em 1933, quando um novo governo radical decretou a gratuidade do ensino secundário.

Noutros países - católicos (como a Espanha ou a Áustria) ou com presença significativa da Igreja Católica (como a Alemanha) -, movimentos similares ao radicalismo francês também lutaram, nas primeiras décadas do século XX, por medidas educacionais destinadas à construção de uma Escola Pública segundo o modelo da Escola Única.

$\mathrm{Na}$ verdade, porém, a Escola Única nunca existiu. A Escola Pública nunca funcionou de fato como uma Escola Única em nenhuma sociedade capitalista. A Escola Única foi, antes, um Mito difundido pelo Estado burguês para estabilizar politicamente a sociedade capitalista. ${ }^{5}$ Pierre Bourdieu nos mostrou, nos seus trabalhos, que a Escola Pública, ao mesmo tempo em que se apresentava à sociedade como Escola Única, direcionava alunos de diferentes classes sociais para trajetórias escolares de tipo diverso. As classes superiores eram encaminhadas para a trajetória escolar longa (que incluía o ensino superior); e as classes inferiores eram relegadas à trajetória escolar curta (que abarcava, no máximo, o ensino técnico de nível médio).

É importante, nesta altura, esclarecer que a submissão da Escola Pública a esse padrão de funcionamento não se deveu a fatores ocasionais, como a má vontade dos governos ou a inépcia do pessoal escolar, e sim a razōes de ordem funcional ou genética. A coexistência, dentro da Escola, entre um discurso igualitário-nivelador e uma ação diferenciadora tem, em primeiro lugar, uma explicação funcional. O Estado capitalista, ao criar a Escola Pública, tem de zelar para que o seu funcionamento preencha as tarefas necessárias à reprodução da divisão capitalista do trabalho: a) encaminhar uma minoria de alunos para os postos dirigentes dentro dessa divisão (isto é, para o trabalho de concepção); b) encaminhar a maioria dos alunos para os postos subalternos dentro dessa divisão (isto é, para o trabalho de execução). Seria incongruente que o Estado capitalista, cujas políticas estão organicamente comprometidas com a reprodução da divisão capitalista do trabalho, implementasse uma política educacional no sentido contrário. Ou seja: cairia em contradição o Estado capitalista que encaminhasse todos os alunos para o desempenho de um trabalho de concepção, pois, nesse caso, a sobre-qualificação chegaria ao seu grau máximo; ou o Estado capitalista que preparasse todos os alunos, simultaneamente, para o desempenho de trabalhos de concepção e de trabalhos de execução, pois, nesse caso, o Estado capitalista estaria atuando, no plano educacional, como se fosse um Estado socialista.

Porém, se o Estado capitalista tem necessariamente de implementar uma política educacional seletiva, que corresponda ao modelo capitalista da divisão social do 
trabalho, ele também tem necessariamente de construir uma aparência igualitária e niveladora para o seu aparelho educacional. É da essência do Estado capitalista se apresentar como representante dos interesses de todos os cidadãos, em todos os níveis de sua ação. Isso implica, no plano específico da ação educacional, que o Estado capitalista se exiba como a instituição que garante a igualdade de oportunidades a todos que queiram se elevar ao topo da vida econômica e social. A construção do Mito da Escola Única é, de resto, especialmente importante para o Estado capitalista, pelo fato de que a escola é uma das únicas instituições da sociedade capitalista que pode ser apresentada de modo convincente às classes populares como instrumento privilegiado da construção da "sociedade aberta", onde todos terão chances de chegar ao topo, desde que se mostrem capazes.

É preciso, em segundo lugar, fornecer uma explicação genética para a formação de uma Escola Pública essencialmente diferenciadora e aparentemente igualitária - niveladora. Alguma classe social deve ter visto a construção de uma instituição educacional que articulasse eficientemente ação diferenciadora e ideologia igualitária - niveladora como um meio de melhorar a sua posição relativa dentro da estrutura social capitalista. Essa classe social foi a classe média; isto é, o grupo social composto pelos trabalhadores nãomanuais. $\mathrm{O}$ contingente de trabalhadores dos serviços entrou em expansão numérica na segunda metade do século XIX, graças aos múltiplos efeitos econômicos e ocupacionais do desenvolvimento do capitalismo. Tal grupo social não poderia, porém, apostar que a sua valorização econômica e social ocorreria de modo automático, pelo simples fato de o trabalho no aparelho de serviços estar aparentemente mais próximo do trabalho intelectual que do trabalho braçal. Foi por isso que ele se envolveu concretamente na construção de uma instituição educacional que deveria preencher simultaneamente duas funções. A primeira função seria a de recompensar, em todos os níveis da atividade pedagógica, a superioridade cultural dos alunos de classe média diante dos alunos proletários. A segunda função seria a de apresentar o desempenho escolar superior dos alunos de classe média, não como decorrência de sua superioridade cultural (relacionada, em última instância, com a sua superioridade econômica), e sim como a pura expressão do seu mérito pessoal.

Não foi, portanto, a burguesia, supostamente movida por um hipotético interesse em qualificar minimamente o trabalhador manual, que moldou a Escola Pública. A montagem da Escola Pública como uma instituição educacional articuladora de uma ação diferenciadora e de uma ideologia igualitária-niveladora foi dirigida pelos agentes ideológicos e políticos da classe média, como a burocracia estatal e os partidos de orientação reformista. ${ }^{6}$ A conseqüência prática da predominância dessa orientação de classe na montagem da Escola Pública foi a adoção de um padrão de ensino em estrita correspondência com os horizontes ideológicos da classe média e com o capital cultural, de natureza pré-escolar e extra-escolar, detido por essa classe social. Examinemos os elementos centrais desse padrão. A linguagem escrita, mais familiar à classe média, era valorizada 
em detrimento da linguagem oral (com a qual o proletariado se achava mais familiarizado). A teoria era radicalmente separada da prática social, especialmente da prática da produção; ou seja, a prática intelectual da abstração era radicalmente distanciada das experiências concretas de vida do proletariado. A familiaridade cultural pré-escolar e extra-escolar era altamente valorizada, o que favorecia objetivamente os alunos de classe média. Apelava-se, de modo consciente ou inconsciente, a um discurso alusivo, acumpliciado com os detentores de certo capital cultural.

Ora, na vigência desse padrão de ensino dentro da Escola Pública, era quase inevitável o fracasso escolar da massa dos alunos não portadores do perfil de classe adequado a tal padrão. Por isso, o fracasso escolar de massa cresceu simultaneamente ao ensino público, gratuito e obrigatório; e se manteve em expansão, não obstante a reiteração oficial do discurso sobre a Escola Única. Mas o fracasso escolar de massa não podia ser oficialmente reconhecido, pelo Estado burguês (agente instaurador da "Escola Única"), como o fracasso do proletariado no seio de uma Escola pequeno-burguesa. Por isso, vários Estados burgueses - com o Estado francês à frente - tenderam a promover, quase simultaneamente à decretação do ensino público, gratuito e obrigatório, a realização de estudos psicológicos que tratassem o fracasso escolar dos alunos proletários como manifestações de algum distúrbio mental. Desse modo, a preocupação governamental com os maus resultados da Escola Pública recém-instaurada levou à produção de conceitos psicológicos imprecisos, como o de "débil mental". 7 Tais conceitos evidenciavam a subordinação da psicologia nascente aos imperativos ideológicos do Estado burguês.

Ao longo da evolução da sociedade capitalista, a classe média atribuiu invariavelmente à Escola Pública uma função ideológica: a de encenar uma competição entre capacidades individuais que permitisse ao conjunto da sociedade atribuir aos alunos bem sucedidos (ou seja: os alunos de classe média, portadores de um montante razoável de capital cultural) o título de detentores de um elevado mérito pessoal. Mas isso não significa que os membros individuais da classe média tenham sempre atribuído à Escola Pública uma utilidade pessoal: em muitos momentos, a classe média pareceu perder o interesse pela Escola Pública, já aberta aos filhos de trabalhadores manuais, como lugar ideal para a educação escolar dos seus próprios filhos.

Se nos servimos das formulações teóricas acima apresentadas, resolvemos facilmente o paradoxo aparentemente inscrito na atitude ambivalente de certos segmentos intelectualizados da classe média (aquilo que Bourdieu chama "a fração dominada da classe dominante") perante a educação. Vejamos em que consiste esse aparente paradoxo. $\mathrm{Se}$, de um lado, tais segmentos defendem intransigentemente a Escola Pública como espaço institucional que parece concretizar a igualdade de oportunidades, de outro lado eles revelam - e fazem-no ao mesmo tempo - uma preferência pessoal pela Escola particular, em nome da necessidade de os seus filhos terem acesso a um "ensino de boa qualidade". Na verdade, não há nenhuma contradição nessa atitude dupla. De um lado, 
professores, intelectuais e profissionais liberais percebem, de modo mais ou menos consciente, que a valorização econômica e social da classe social à qual pertencem (a classe média) exige a manutenção, dentro da sociedade capitalista, de espaços formalmente democráticos, aptos a encenar uma competição livre de talentos individuais; e têm certeza antecipada de que os seus filhos sairão vencedores dessa competição. De outro lado, esses segmentos buscam conscientemente a melhor trajetória individual possível para os seus filhos dentro da classe média; por isso, optam por “escolas de alto nível”, não contaminadas pela presença do proletariado, visto como um fator permanente de rebaixamento da qualidade do ensino. Há, portanto, uma diferença entre a perspectiva da classe social como um todo (isto é, aquilo que poderíamos denominar a ideologia da classe social) e as ações individuais dos membros dessa classe, implementadas à luz dessa perspectiva. É essa diferença que explica a preferência pessoal de defensores ardorosos da Escola Pública pelas escolas particulares. ${ }^{8}$

Para a classe média, portanto, seria um absurdo, do ponto de vista social, a supressão da Escola Pública, seguida da privatização integral do aparelho educacional. Caso toda a educação escolar fosse paga, e não gratuita, ficaria evidente para o conjunto da sociedade que a inserção de certos indivíduos no topo da divisão capitalista do trabalho é o resultado concreto final da posse de recursos econômicos, metamorfoseados sucessivamente em capital cultural e em capital escolar. A rigor, a classe média se inclina predominantemente para uma fórmula conciliatória no terreno da educação; ela consiste em aceitar a coexistência, em proporções que podem variar conforme a conjuntura social e política, entre ensino público e ensino privado.

Do ponto de vista ideológico, a classe média precisa sempre da presença da Escola Pública como espaço formalmente democrático, pois essa instituição, ao encenar a competição de talentos individuais, valoriza econômica e socialmente os bem sucedidos; e estes, nunca é demais lembrar, são majoritariamente indivíduos pertencentes à classe média. Do ponto de vista das preferências pessoais no terreno da educação escolar, os membros individuais da classe média tendem a oscilar entre a Escola Pública e a Escola Privada, conforme a conjuntura. Nas fases de baixa afluência do proletariado à escola ou nos momentos de declínio dos rendimentos reais da classe média, os seus integrantes podem escolher para os seus filhos a Escola Pública como uma opção razoável; já nas fases ou momentos de democratização relativa do acesso à educação pública, os membros da classe média podem direcionar crescentemente os seus filhos para escolas particulares, encaradas como um refúgio contra a "queda de nível", provocada na Escola Pública pela presença crescente do proletariado. 


\section{A CLASSE MÉDIA E A ESCOLA PÚBLICA NO BRASIL}

Voltemos agora à análise da Escola Pública no Brasil. Imediatamente após a Revolução de Trinta, os agentes ideológicos e políticos da classe média (tenentes e nacionalistas no plano político, escolanovistas no plano especificamente educacional) se lançaram, antes e depois do processo constituinte, numa ação pela construção de um sistema de educação pública fundado no princípio do ensino (primário) público, gratuito e obrigatório. Tais agentes, ao mesmo tempo, reconheciam como legítima a existência do ensino privado; e sustentavam que a Escola Pública e a Escola Privada poderiam ser encaradas como instituições complementares (isto é, em coexistência pacífica), e não concorrentes (isto é, não-envolvidas, cada uma delas, numa luta sem trégua pela supressão da outra).

$\mathrm{Na}$ verdade, a oposição das classes dominantes à expansão e ao fortalecimento da Escola Pública se conjugou à dupla atitude da classe média perante o ensino público; essas duas posiçōes diferentes, exteriorizando-se na mesma conjuntura, determinaram a linha geral de desenvolvimento do sistema educacional brasileiro no período pós-trinta. É, portanto, importante sublinhar que a classe média, em razão de sua atitude dupla diante da educação escolar, acabou se configurando como um agente importante tanto do ensino público, quanto do ensino privado. Medidas importantes de democratização do ensino público, como o fim do exame de admissão ao ginásio e a decretação de oito anos de escolarização obrigatória (reformas promovidas pelo regime militar), ou a enorme expansão das vagas no ensino fundamental (orientação implementada na Nova República), exprimiam não o ponto de vista educacional das classes dominantes, e sim a pressão social difusa dos "formadores de opiniāo", representativos da classe média, ou então a pressão social politicamente organizada, canalizada pelos agentes ideológicos e políticos da classe média, como o movimento docente, as reuniōes de cientistas, as corporaçōes profissionais, etc.

Também é essencial mencionar que a existência de uma importante clientela de classe média, disposta a pagar por educação escolar, foi um fator decisivo para a expansão do ensino privado, a taxas variáveis, da década de 1940 até a década atual. Essa pressão da demanda de classe média por mais ensino privado se explica pelo fato de que a expansão da Escola Pública, ao promover a incorporação crescente das classes trabalhadoras manuais, não só revitalizou o Mito da Escola Única, indispensável do ponto de vista ideológico à valorização econômica e social da classe média, mas também determinou um "rebaixamento do nível de ensino", inaceitável em termos pessoais para os membros individuais da classe média.

\section{O FUTURO DA ESCOLA PÚBLICA}

Chegamos, aqui, ao impasse vivido pela Escola Pública no Brasil atual. Para esse impasse não há solução possível dentro do modelo capitalista de sociedade. A democratização do acesso à educação pública, que se compatibiliza plenamente com os 
horizontes ideológicos da classe média, determina a manutenção, se não o crescimento da taxa de fracasso escolar, já que a massa dos proletários ingressantes na Escola Pública não tem como se adaptar ao padrão de ensino (típico da classe média) que lhe é imposto. A alta taxa de fracasso escolar tende a provocar um rebaixamento das expectativas dos professores com relação aos alunos; e, conseqüentemente, um rebaixamento da qualidade do ensino dentro do padrão vigente. Esse rebaixamento, por sua vez, afugenta a clientela de classe média, cuja motivação individual é o sucesso especificamente dos seus filhos na vida econômica e profissional. Isso significa, em última instância, que a expansão e a democratização do ensino público tendem a realimentar continuamente o ensino privado.

Esse moto perpétuo pode ser rompido em certas conjunturas. É o que ocorre, por exemplo, quando o poder aquisitivo da classe média cai a ponto de dificultar a sua permanência na escola privada. O circuito, porém, tende a se restabelecer e a durar, enquanto estiver de pé o modelo capitalista de sociedade. Não há, portanto, nenhuma solução técnica para o problema básico da Escola Pública na sociedade capitalista, pois esse problema, como procuramos demonstrar neste texto, é um problema social, e não um problema técnico. Mantido o padrão de classe média do ensino, as medidas destinadas a promover a melhoria da qualidade de ensino só farão ampliar as exigências e dificuldades escolares para os alunos proletários; e levarão a um incremento do fracasso escolar.

A melhoria interna da Escola Pública existente produzirá como resultado máximo tão-somente o aumento das chances de uma minoria de alunos, pertencentes à classe média, no exame vestibular. A transformação interna que faria da Escola Pública uma verdadeira escola a serviço da maioria social exigiria a ruptura do compromisso orgânico do aparelho educacional de Estado com a reprodução da divisão capitalista do trabalho. Uma Escola a serviço do proletariado resgataria a experiência concreta de vida e de trabalho do proletariado, integrando-a ao processo de produção e de transmissão de conhecimentos. Tal Escola prepararia todos os alunos, simultaneamente, para o exercício do trabalho de concepção e do trabalho de execução.

Pode-se facilmente imaginar que não seria o Estado burguês o tipo de Estado capaz de levar a Escola Pública a romper com a divisão capitalista do trabalho: essa revolução na Escola só poderia ser promovida por uma democracia socialista de massa.

\section{Notas}

1. Dados da pesquisa da Unesco, realizada em 13 capitais brasileiras e coordenada por Miriam Abramovay e Mary Garcia Castro, foram reproduzidos no jornal Folha de São Paulo, caderno "Cotidiano", p. C 4, de 30 de abril de 2003.

2. Não nos interessa, aqui, mapear as objeçôes levantadas com relação aos dados sobre a evolução do acesso ao ensino fundamental no Brasil. A comprovação da falsidade dos dados oficiais não alteraria, no fundamental, a direção de nossa análise crítica sobre a Escola Pública no Brasil atual. 
3. É difícil, nas análises concretas, estabelecer um corte rigoroso entre as classes sociais. Aqui, ao nos referirmos à classe média, estaremos visando os seus dois segmentos mais emblemáticos (isto é, aqueles que corporificam mais claramente a eqüidistância desse grupo social com relação à classe capitalista e aos trabalhadores manuais): a classe média-média e a classe média-alta.

4. Os resultados principais dessa pesquisa foram reproduzidos no jornal Folha de São Paulo, caderno "Cotidiano", página C 1, de $1^{\circ}$ de agosto de 2004.

5. O Mito da Escola Única é analisado por Christian Baudelot e Roger Establet em L'école capitaliste en France, Paris, François Maspero, 1971, capítulo 1, "Les illusions de l'unité de l'école".

6. O partido radical francês, que teve atuação destacada da década de 1900 à década de 1930 , era altamente representativo da classe média pela sua composição social e pela sua ideologia. Tal partido assumiu um papel de vanguarda na luta pela laicização do ensino e pela instauração da Escola Única na França.

7. Sobre esse ponto, consultar Michel Tort, O quociente intelectual, Lisboa, Editorial Notícias, 1976; e Monique Vial, "Um desafio à democratização do ensino: o fracasso escolar", in: Zaia Brandão (Org.). Democratização do ensino: meta ou mito?, 3. ed. Rio de Janeiro: Francisco Alves, 1987.

8. Aborda-se, de modo mais detalhado, a ambivalência da classe média diante da Escola Pública no artigo "Classe média e escola capitalista", publicado em Crítica Marxista, Rio de Janeiro: Ed. Revan, n. 21, novembro de 2005.

\section{Referências}

BAUDELOT, Christian; ESTABLET, Roger. L'école capitaliste en France. Paris: Maspero, 1971.

SAES, Décio Azevedo Marques de. Classe média e escola capitalista. Crítica Marxista, Rio de Janeiro: Ed. Revan, n. 21, p. 97-112, nov. 2005.

TORT, Michel. O quociente intelectual. Lisboa: Editorial Notícias, 1976.

VIAL, Monique. Um desafio à democratização do ensino: o fracasso escolar. In: BRANDÃO, Zaia

(Org.). Democratização do ensino: meta ou mito? 3. ed. Rio de Janeiro: Francisco Alves, 1987, p.11-23. 


\section{Public school and social classes in Brazil today}

Abstract

This paper deals with school failure as a social fact in present day Brazil; which means that we must look for its social causes. Our conclusion is that, by increasing considerably the offer of public schooling at primary level and at the same time maintaining the standard of middle-class schooling, there can only be a predominance of the tendency to maintain and even increase school failure of lower class pupils, incapable to rise to the standard of teaching defined by the capitalist State apparatus. And it is difficult to imagine the reformulation of these standards, since the middle class, very influent in the educational field, needs the school failure of the other social classes in order to intensify its own economic and social value.

Keywords: Public school. Middle class. Working class. School failure.

\section{L'école publique et les classes sociales au Brésil d'aujourd'hui}

\section{Résumé}

Ce texte traite de l'échec scolaire comme phénomène social au Brésil d'aujourd'hui; ce qui implique chercher ses causes sociales. Notre conclusion est que, si l'on augmente considérablement l'offerte d'éducation publique au niveau primaire et, en même temps, maintient le niveau de la classe moyenne d'enseignement, il pourra seulement prédominer la tendance à la manutention et voire même l'augmentation de l'échec scolaire tel que défini par l'appareil de l'État capitaliste. Il est difficile d'imaginer la reformulation de ce niveau, étant donné que la classe moyenne, hautement influente dans le champs éducationnel, a besoin de l'échec scolaire des autres classes sociales pour intensifier sa propre valorisation économique et sociale.

Mots clefs : École publique. Classe moyenne. Prolétariat. Échec scolaire.

\section{Escuela pública y clases sociales en el Brasil actual}

Resumen

Este texto vista tratar el fracaso escolar en el Brasil actual como un fenómeno social, lo que implica buscar sus causas sociales. Nuestra conclusión es que, ampliándose considerablemente la oferta de educación pública a nivel fundamental y, al mismo tiempo, manteniéndose el patrón de clase media de la enseñaza, sólo puede predominar la tendencia a la manutención y al aumento del fracaso escolar de los niños de origen popular, incapaces de elevarse al patrón de enseñanza definido por el aparato de estado capitalista. Y es dificil imaginar la reformulación de ese patrón, ya que la clase media, con gran influencia en el campo educacional, necesita del fracaso escolar de las otras clases sociales para intensificar a su propia valoración económica y social.

Palabras-clave: Escuela pública. Clase media. Proletariado. Fracaso escolar.

Recebido em: 26.08 .2008

Aceito em: 04.12.2008 